\title{
On combinations of silver chloride, bromide, and iodide with colouring-matters
}

\section{Cary Lea}

To cite this article: M. Cary Lea (1885) On combinations of silver chloride, bromide, and iodide with colouring-matters, Philosophical Magazine Series 5, 19:118, 229-231, DOI: $10.1080 / 14786448508627670$

To link to this article: http://dx.doi.org/10.1080/14786448508627670

曲 Published online: 29 Apr 2009.

Submit your article to this journal

Џ Article views: 3

Q View related articles $₫$ 
their structure but also in their mineralogical constitution. Among them occur examples of the rocks which have received the names of dunite, picrite, and lherzolite, with some curious types composed of felspar and olivine.

Among the older peridotites of Scotland a new and very interesting type is described from near Loch Scye in Caithness. It appears to have been originally a mica-picrite, but the whole of the original minerals have been converted into paramorphs, firstly by schillerization and subsequently by amphibolization and serpentinization.

In conclusion, it was pointed out that the discrimination between the effects of the changes described as schillerization and those known as uralitization, amphibolization, serpentinization, and kaolinization is of the utmost importance, not only to the petrographer but to the mineralogist.

2. "Boulders wedged in the Falls of the Cynfael, Ffestiniog." By T. Mellard Reade, Esq., F.G.S.

This paper briefly deseribed certain phenomena of stream-denudation observed in the bed of the Cynfael, which has cut a deep channel through the Lingula Flags, the course of the channel being mainly dependent on the jointing of the rock. In one spot the upper beds at the top of the gorge have slid upon the lower along their dip, about $10^{\circ}$ to north by east, so as to project over the stream like a corbel; and advantage has been taken of this to form a bridge by means of a slab of rock laid from the projecting mass to the top of the opposite bank. At anothor point several very large boulders are stuck fast in the channel, and the stream flows beneath them. The boulders could not possibly have been carried down the existing gorge, and they had not, the author believed, fallen from above. He suggested that they might have been carried down by the aid of ice, probably in the glacial period, when the stream ran in a wider channel, and that they had been polished by the action of the water.

XXVIII. Intelligence and Miscellaneous Articles.

ON COMBINATIONS OF SILVER CHLORIDE, BROMIDE, AND IODIDE WITH COLOURING-MATTERS. BY M. CARY LAA, PHILADELPHIA.

WHILE studying these silver-salts in May last, I found that they

had the remarkable property of entering into chemical combination with many colouring-matters very much in the same way that alumina does, though not to the same extent, forming what may be called lakes. It is only necessary to bring freshly precipitated and still moist silver-salt into contact with the colouring-matter, or to make the precipitation in the presence of the colouring-matter if the latter is not precipitated by silver nitrate, when the combination takes place and the colouring-matter cannot be washed out by any amount of washing. A prolonged absence following immediately after has prevented the continuation of the investigation. 
It is still incomplete, and the leading facts only are mentioned here to take date.

Not all colouring-matters are capable of uniting with the silversalts, but the number of those that do so unite is considerable. What is curious and tends to show that the combination is intimate, is that the colour assumed by the silver-salt is not always that of the dye, but may differ from it considerably. Also the three silversalts may be differently coloured by one and the same colouringmatter.

More frequently, however, colouring-matters impart their own shade or something approaching to it. Thus, silver bromide precipitated in presence of excess of silver nitrate takes from anilinepurple a strong purple colour ; from cardinal-red a bright flesh or salmon-colour; from naphthaline-yellow a light yellow colour ; from eosin a brilliant pinkish or salmon; and so on.

Different specimens of the same colour gave sometimes quite different results: thus, silver bromide precipitated in presence of silver nitrate was dyed by one specimen of methyl-green to a bluish green. Another specimen of the same colour obtained from a different source coloured the same silver-salt a deep purplish shade. Silver iodide showed the same difference.

Sixteen years ago I proposed to colour or stain the photographic film in order to modify its behaviour towards light, principally to prevent blurring or irradiation*.

Of many colouring-matters then tried, the best proved to be litmus coloured red by acetic acid. This was very effectual for the purpose, and was long used by others as well as myself. So far as I have been able to ascertain, it was the first suggestion made of this mode of acting on the sensitive plate. Since then, staining the film has been found to have other applications; and many others have experimented in this direction, in most cases with a view to alter its sensitiveness relatively to the different colours of the spectrum. Major Waterhouse was, I believe, the first to recognize this effect.

Dr. John W. Draper appears to have first advanced the view that substances sensitive to light are affected by the rays which they absorb. There is much to support this theory, although it cannot be considered as definitely established.

Some years since Dr. H. W. Vogel expressed the opinion that, when sensitive films were washed over with solutions of colouringmatters, the films gained sensitiveness to those rays of the spectrum which the colouring-matters absorb, with this condition-that the colouring-matter in question must be capable of combining with $\mathrm{Cl}$, $\mathrm{Br}$, or $\mathbf{I}$, as the case might be. My own results were different. I found that the action of the rays was profoundly modified by colouring the film; but the result did not seem to conform to any law, and as often contradicted Vogel's view as agreed with it.

Vogel's theory necessitates the assumption that the colour

* British Journal of Photography, 1868, pp. 210, 506; 1870, p. 145 \&c. 
imparted to the silver-salt is identical with that of the dye used; and, as has been shown above, that by no means follows. He supposed that the capacity of any given colour to influence the silver-salt depended upon its tendency to combine with $\mathrm{Cl}, \mathrm{Br}$, and $\mathrm{I}$; whereas, as we have above seen, its action most probably depends upon its ability or inability to combine with the silver haloid.

But the principal source of error has arisen from the fact that when the film is stained, the effect is necessarily a confused one. Besides any influence that may be exerted on the particles of silver haloid, these particles are virtually behind a colour-screen, which must materially modify the nature of the light that reaches then, and the final effect must necessarily be a combination from two distinct causes. Moreover, the colour in the film tends to arrest precisely those rays to which it is proposed to render the silver-salt more sensitive; a consideration of the utmost importance, for the one action tends to counteract the other, and thus leads to inextricable confusion. From a system of experiments so faulty no just conclusions could be drawn.

Whether, with these sources of error eliminated, Draper's view, that a sensitive substance is influenced by those rays which it absorbs, can be applied to these new combinations which I have here described, is a matter on which $I \mathrm{am}$ not prepared to express an opinion, having been, much to my regret, unable as yet to examine the question. It seems a priori probable; but in that case it is important to observe that the effect will depend, firstly, upon the capacity of the dye to combine with the silver haloid, and, secondly, not on the proper colour of the dye isolated, but on the colour that the silver haloid acquires under its action, which, as we have already seen, may be something quite different from the colour of theoriginal dye.

I. have observed that the silver-salts are greatly changed by conversion into lakes, even when the colour imparted is but faint. They become in some cases much more finely divided and remain long in suspension. In one case at least a great increase of sensitiveness to light for development was observed. Later I shall hope to give more definite details on these points.

In the above facts will donbtless be found an explanation of many of the anomalies in the behaviour of coloured films which have caused such wide differences of opinion. And the new modes of operating deducible from the reactions here described will, I think, be found of extended utility. Silver-salts can be dyed first and emulsified afterwards; and the ability to colour the sensitive salt to any shade with certainty, and without introducing a counteracting influence into the film, gives a new power in photochemistry. -Silliman's American Journal, January 1885.

\section{ON A SEIENIUM-ACTNNOMETER. BY M. F. MORIZE, OF RIO JANEIRO.}

The object of this instrument is to measure the relative intensities of solar luminous rays at different heights on the horizon. 